\title{
El concepto de praxis en Marx: La unidad de ética y ciencia
}

\author{
Luis Armando González
}

"La sociedad burguesa cree haber refutado la critica del capitalismo que Maxx habla hecho... La tesis de Marx sobre el carácter autodestructor del sistema ya no convence...

"Se trata del retorno de la critica del capitalismo de Max. Electivamente, el mercado ha resultado ser un automatismo que, al producir la riqueza, destruye progresivamente las fuentes de todas las riquezas: el hombre y la naturaleza".

Franz J. Hinkelammert

\section{Introducción}

El problema de la praxis es central en el pensamiento de Karl Marx. En electo, es una cuestión central porque desde ella es posible superar aquellas lecturas cientificistas y criticistas de su pensamiento. Es decir, permite superar las interpretaciones en las que Max aparece como un mero economlsta -como continuador de Ricardo y Smith-o en las que aparece como un pensador humanista, preocupado únicamente por las lacoraclones que la dinámica capltalista produce en los trabajadores. Cientamente, Marx efectúa un riguroso análisis clentlfico del funclonamlento estructural del slstema capitalista, pero también se enfrenta criticamente a los efectos deshumanizantes del sistema. $Y$, desde ese anállsls cientifico y esa critlca humanista, propone un nuevo proyecto soclo-hlstórico -un nuevo "horizonte utópico"- en el cual han de ser 
superados los lastres de la "pre-historia" de la humanidad. En Marx, pues, "La explicación sociológica y la reflexión ética van a la par y, juntas, fundan una teoria operativa de las causas, las condiciones y los objetivos de la revolución social moderna" ${ }^{m}$. Es decir, en su pensamiento, el análisis científico del capitalismo está vinculado orgánicamente a la crítica radical del mismo y a un proyecto revolucionario. La reflexión científica conduce a un enjuiciamiento ético del sistema, $y$, ambos aspectos, exigen una actuación práctico-revolucionaria que incida efectlvamente en la superación estructural del orden establecido. Etica y ciencia se articulan, para Marx, en una unidad indisoluble: la expresión de esta unidad es la noción de praxis.

De esta forma, el concepto que unifica y da sentido a la labor teórica y politica de Maxx es justamente el concepto de praxis. Este concepto es el que permite fundar la concepción materialista de la historia. $Y$ esto es asi porque, para Marx, la praxis es la actividad humana fundamental, en virtud de la cual el hombre produce la realidad histórica y se produce a si mismo. En este sentido, la idea de praxis tiene una dlmensión antropológica esencial. La praxis es justamente lo que define al hombre como tal. El hombre, para Marx, es un ser de la praxis (G. Petrovic).

La noción de praxis, sin ambargo, es una noción compleja. Es decir, es una noción unitaria y diversa. Praxis no es ni "practicismo", ni "criticismo", ni cientificismo", sino que es, unitariamente, la actividad humana -práctico-sensiblo - en la que se articulan un determinado conocimiento de la realidad social, una crítica radical a dicha realidad y un proyecto para su transformación. Como to formula Adolío Sánchez Vázquez: la praxis es "un proyecto de transformación de la realidad a partir de una crítica radical de lo existente, basándose a su vez ambos aspectos en un conocimiento de la realidad que se pretende transformar $^{m 2}$. Alli donde se dan orgánicamente esos tres aspectos tenemos strictu sensu praxis; esto es, tenemos la actividad humana más auténtica, la actividad humana consciente mediante la cual el hombre transforma critica y revolucionariamente lo existente y se transforma a sl mismo. Esta es una actividad "crítico-práctica" en la cual se opera la "coincidencia del cambio de las circunstancias con el de la actividad humana o cambio de los hombres mismos"s. Es por esto que, con razón, Kosik puede decir que "La praxis es la esfera del ser humano".

Tal como ha sido planteada, la idea de praxis se vuelve un instrumento de gran importancia para entender la obra de Marx. Por un lado, permite captar la continuidad y unidad del pensamiento maxiano, desde los textos de juventud ("La Cuestión Judia", la "Contribución a la 
crítica de la filosofia del derecho de Hegel", Los manuscritos de 1844) hasta los escritos de madurez (Los Grundrisse, El Capital). En este punto, desde la noción de praxis se pueden cuestionar todas aquellas interpretaciones unilaterales o que parcializan el pensamiento maxiano. Estas interpretaciones parcializadas pueden ir en una dirección "teoricista" (Althusser), en una dirección "criticista" y "humanista" (Marcuse) o en unà dirección "política" (Lenin). En todas estas "lecturas" se privilegia una dimensión de Marx, en detrimento de su integralidad como crítico del capitalismo, hombre de ciencia y político. Por otra parte, la idea de praxis ayuda a entender la totalidad de la obra realizada a to largo de su vida. Es decir, es un instrumento que permite sistematizar y exponer los logros más fecundos de ese gran revolucionario y teórico del capitalismo que fue Karl Marx.

Ateniéndonos a la noción de praxis que hemos propuesto, la actividad de Marx cobra pleno sentido a partir de los siguientes tres objetivos que él se propone: conocer la lógica estructural del modo de producción capitalista; criticar los efectos deshumanizadores de la misma; y proponer - desde ese saber y esa crítica - un proyecto de sociedad en el que esa lógica fuese superada en sus raices. Estos son los momentos esenciales de la gran tarea asumida por nuestro autor; y la prioridad la tiene sobre todo la superación radical del capitalismo, porque Marx es antes que otra cosa un revolucionario, un militante político. Su praxis sólo se entiende a partir de esta intención fundamental. ¿Cómo aparecen en su pensamiento los momentos de la praxis que hemos planteado arriba?

\section{El anállsls clentifico del capltallsmo}

Es indudable que el trabajo de toda la vida es determinar la lógica especiffica de ese objeto específico que es el modo de producción capitalista. Es decir, su interés fundamental es conocer la lógica estructural del capitalismo; su preocupación es establecer "la differentia specifica del capitalismo a las 4ormas que preceden a la producción capitalista' y la de la peculiar incidencia de las máquinas en el sistema económico social moderno"s. De lo que se trata es tanto de "tijar el modelo de funcionamiento del capitalismo (...), como de predisponer el modelo conceptual para la reconstrucción de los sistemas sociales pre-modernos ${ }^{\text {to }}$.

Sin ambargo, en este análisis del capitalismo no se trata de contribuir a su conservación; no se trata de contribuir a que el sistema funcione con mayor eficiencia. Los que lean asi a Marx encontrarán en su pensamiento innumerables fallas "técnicas". Lo que nuestro autor qule- 
re es desentranar las contradicciones estructurales del sistema y, justificar desde ellas, la necesidad de su supresión.

\subsection{La contradicción fuerzas productlvas-relaclones soclales de producelón.}

La totalidad del modo de producción capitalista, según Marx, se edifica sobre una "base contradictoria": la contradicción entre las fuerzas productivas y las relaciones sociales de producción. Esta tesis encuentra ya una de sus primeras formulaciones en La ideología alemana. "En el desarrollo de las fuerzas productivas, se llega a una fase en la que surgen fuerzas productivas y medios de intercambio que bajo las relaciones (sociales) existentes, sólo pueden ser fuente de males, que no son ya tales fuerzas de producción, sino más bien fuerzas de destruc-

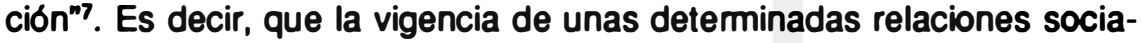
les - como las de carácter privado que imperan en el capitalismo- se convierten, en una fase histórica determinada, en un obstáculo para el desarrollo de las fuerzas productivas; convirtiéndose por ello en una fuente de "males históricos". Más aún, dichas relaciones sociales hacen de las fuerzas productivas "fuerzas de destrucción".

El capitalismo - a medida que se expande - tiende a agudizar más esa contradicción. Y el "mal mayor" que trae consigo es el de posibilitar el nacimiento de una clase social "condenada a soportar todos los inconvenientes de la sociedad sin gozar de sus ventajas, que se ve expulsada de la sociedad y obligada a colocarse en la más resuelta contraposición a todas las demás clases; una clase que forma la mayorla de todos los miembros de la sociedad y de la que nace la consciencia de que es necesaria una revolución radical"'s. Esta clase, como se sabe, es la clase proletaria; la clase que soporta las injusticias micas, sociales y políticas - generadas por la dinámica contradictoria del sistema capitalista de producción. El nacimiento de esta clase que se contrapone a todas las demás clases no se entiende si no es por la lógica de las relaciones sociales que imperan en el capitalismo, las cuales producen y reproducen la apropiación privada de la producción social y, con ello, la concentración de la riqueza en manos de la burguesia y la expansión de la miseria en manos de los sectores proletarios.

La idea maxxiana de que el capitalismo se edifica sobre una base contradictoria, específicamente sobre la contradicción entre las fuerzas productivas y las relaciones sociales de producción, aparece también en los trabajos de madurez de Max, como lo son los Grundrisse y El Capital. 
En estos escritos, dicha contradicción se expresa, por un lado, en el carácter cada vez más socializado del proceso de producción capitalista y, por otro, en la forma privada de apropiación que impera en sociedad burguesa. Es decir, en el capitalismo las fuerzas productivas entran en un proceso de socialización creciente que es antagónico con la apropiación privada de los productos sancionada por las relaciones sociales. Como dice Marx: "el régimen capitalista se nos presenta, de una parte, como una necesidad histórica para la transformación del proceso de trabajo como un proceso social, de otra parte esta forma social del proceso de trabajo aparece como un método empleado por el capital para explotario con más provecho, intensificando su fuerza productiva"m.

La dinámica económica capitalista, a medida que se perfecciona la división social del trabajo y se desarrolla el maquinismo, tiende a socializar cada vez más el proceso de producción, tiende a hacer del trabajo "una fuerza productiva social", lo cual hace posible que la "cooperación" aparezca como una "forma específica del proceso capitalista de producción"10. Pero esta dinámica socializadora de las fuerzas productivas es antagónica con la forma privada de apropiación. En el capitalismo, "La cooperación de obreros asalariados tiene, pues, como condición material la concentración de grandes masas de medios de producción en manos de cada capitalista, el alcance de la cooperación o la escala de la producción depende del grado de concentración de estos elementos $^{m 11}$.

Por otra parte, si bien es cierto que la contradicción fundamental del modo capitalista de producción es la contradicción entre la socialización de la fuerzas productivas y la apropiacion privada de la riqueza social, no es menos cierto que sobre la misma se configuran otras contradicciones menos importantes, como es el caso de la que existe entre la producción y el consumo. Entre producción y consumo existe, efectivamente, una relación antagónica: mientras que la producción tiende a crecer aceleradamente, el consumo es cada vez más restringido para las grandes mayorias de la sociedad. "La contradicción entre la socialización de hecho de la produccion se manifiesta como la contradicción entre la tendencia al desarrollo ilimitado de las fuerzas productivas y los estrechos límites en que queda encerrado el consumo"12. Más aún, "EI modo de producción capitalista es así el primero donde la producción parece convertirse en un fin en si" 13; es decir, la producción sigue una dinámica que es independiente de las posibilidades reales de consumo de la sociedad.

Sin embargo, la producción no puede independizarse totalmente del 
consumo. $Y$ en el capitalismo, "las crisis periódicas recuerdan duramente que, a la larga, la producción no puede separarse completamente de las posibilidades de consumo solvente de la sociedad"14. En la sociedad burguesa estas posibilidades de consumo son estrechas y limitadas; y en este sentido no tienen la capacidad de absorver la creciente disponibilidad de mercancias, fruto del desarrollo incesante de la productividad. Este quiebre entre producción y consumo encuentra su expresión clásica en las llamadas 'crisis de sobreproduccion', en las que la superabundancia de mercancias en un sector determinado de la economia no se ve compensada por un consumo equivalente. Por bo tanto, al no encontrar consumidores, las mercancias no pueden ser vendidas. Al generarse este fenómeno en gran escala se produce la crisis de sobreproducción: la sociedad ha producido más de lo que puede consumir y se hace necesario destruir los excedentes, suprimir determinadas industrias o ramas de la producción, etc., lo cual agrava aún más la crisis la sociedad.

La consecuencia más grave de la situación de crisis que hemos descrito es que conduce a un "quiebre" en la lógica de la producción burguesa, cuya finalidad última consiste en obtener una tasa más elevada de trabajo impago o plusvalía. En efecto, el capitalista no puede embolsarse su cuota de plusvalia, obtenida en el proceso de producción, si no es vendiendo sus marcancías. Sólo vendiendo la totalidad de las mercancias producidas puede el capitalista realizar efectivamente su cuota de plusvalia. "El excendente (surplus) no surge de la circulación, tan sólo en ella se realiza"15. Es decir, "La masa total de mercancias, el producto total..., necesita ser vendida. Si no logra venderse o sólo se vende en parte o a precios inferiores a los de la producción, aunque el obrero haya sido explotado, su explotación no se realiza como tal para el capitalista, no va unida a la realización, o solamente va unida a la realización parcial de la plusvalia estrujada, pudiendo incluso llevar aparejada la pérdida de su capital en todo o en parte. Las condiciones de la explotación directa y las de su realización no son idénticas"18.

Por otra parte, entre producción y circulación-consumo existe una unidad indisoluble. "El capital es la unidad inmediata del producto y el dinero, o mejor entre la producción y la circulación"17. Ahora bien, la dinámica de las relaciones de producción capitalista instaura una "nuptura" en la unidad producción-circulación; esto es, en la unidad "explotación-realización". En el capitalismo, a medida que se "desarrolla la capacidad productiva, más choca con la angosta base sobre las que descansan la condiciones de consumo"18. Esta es una contradición que atraviesa al modo capitalista de producción; es una contradicción que 
se opone, al interior del propio capitalismo, a la lógica de la valorización del capital. Este antagonismo plantea la necesidad de superar la Kogica del sistema de producción burgués e instaurar un sistema social en el cual la producción y la distribución-consumo sean estructuralmente armónicas.

En resumen, para Marx el capitalismo es una realidad esencialmente contradictoria. La contradicción fundamental consiste en el anatagonismo existente entre unas fuerzas productivas cada vez más socializadas y en crecimiento cualitativo y cuantitativo creciente y unas relaciones sociales de carácter privado que por ser tales imponen restricciones insalvables al desarrollo de aquellas. Las crisis de sobreproducción son la expresión más evidente de esta contradición: estas crisis ponen de manifiesto que la sociedad está produciendo más de lo que efectivamente puede consumir. Desde la perspectiva del capitalista, al producirse la crisis le es imposible realizar su cuota de plusvalia y, por lo tanto, le es imposible valorizar su capital. No le queda más opción que abandonar el sector afectado por la crisis y ubicar su capital en un sector distinto, que le permita extraer trabajo impago o plusvalia. A la clase obrera, por el contrario, esa fisura estructural del sistema le va planteando cada vez más la exigencia de superar revolucionariamente el orden establecido e instaurar un nuevo orden social.

\subsection{La teorla del valor}

Un elemento central del análisis maxiano del capitalismo to constituye la teoria del valor. Es a partir de esta teoria que Marx se distancia definitivamente -en los Grundrisse y El Capital de la oconomia política clásica. Que se distancie no quiere decir, por supuesto, que pierda todo vínculo con sus antecesores. Cientamente, hay una continuidad esencial: para los clásicos y para Marx el trabajo humano es la fuente de todo valor. Pero Marx introduce elementos de análisis e interpretación novedosos que le permiten superar las limitaciones de la concepción del problema del valor en Adam Smith y David Ricardo. "Efectivamente, Marx, por un lado, resalta y replantea aquellos aspectos de la investigación clásica que tuvieron el peso y el alcance de auténticos descubrimientos científicos y, por otro, libera definitivamente dicha investigación de la escoria y los límites burgueses que motivaron sus insuficiencias y contradicciones insuperables ${ }^{18}$.

Los economistas clásicos parten de la sociedad burguesa. Su interés fundamental es determinar, primero, cuál es el origen de la riqueza en la sociedad moderna y, segundo, explicar cuál es el mecanismo de intercambio de esos productos del trabajo que son las mercancias. 
Adam Smith responde a lo primero afirmando que la riqueza burguesa 'tiene su origen... precisa y exclusivamente, en el 'trabajo' y en una forma específica de trabajo, el trabajo socialmente dividido, cuya finalidad es la producción de mercancias y el cambio"19. Es decir, para Smith, a diferencia de la tradición económica anterior, la base de la riqueza está constituida por el trabajo productivo, capaz de tijar en el valor de las mercancias que produce un valor "excedente" al suyo propio ${ }^{20}$. De qué naturaleza es ese trabajo productivo que en la sociedad moderna genera un valor excedente es algo que Smith no logró. Por otra parte, Smith en su intento de explicar el mecanismo del intercambio de las mercancias formula su teoría del valor; y localiza el origen de ese valor "en determinadas cantidades de trabajo"21 que la mercancía posee. EI valor "depende de la cantidad de trabajo que una mercancia adquiere, o viceversa, que viene a ser lo mismo, de la cantidad de trabajo que dicha mercancia está en grado de diponer, 'de poner en marcha"zen.

Como dice el propio Adam Smith: "Téngase en cuenta que la palabra valor tiene dos sentidos distintos, y que unas veces expresa la utilidad de un determinado objeto y otras la capacidad que para la compra de otros artículos proporciona la poseción de ese objeto. Una de esas acepciones podría llamarse 'valor en uso'; la otra, 'valor en cambio"zes. Por tanto, Smith "ve en el análisis del valor de cambio el instrumento más eficaz para el análisis de la sociedad del cambio, de la sociedad capitalista"24.

Para Adam Smith, pues, el valor de cambio de una mercancla depende de la cantidad de trabajo que la misma adquiere: "se trata del 'poder', que la posesión de ese objeto comporta, de adquirir otros bienes. Por lo tanto, el valor de una mercancia cualquiera respecto a quien la posee y que no pretenda utilizarla o consumirla él mismo, es igual a la cantidad de trabajo que dicha mercancia le coloca en grado de adquirir o disponer. El trabajo es, pues, la medida real del valor de cambio de todas las mercancias"25. Y lo que determina en último término el valor de cambio de las mercancias es el "valor del trabajo" que se expresa en el salario. Es decir, la medida de los valores es para Smith el valor del trabajo: el valor de las mercancias se mide "según la cantidad de trabajo necesaria para su producción, en cuanto que coincide con la cantidad de trabajo que con dicha mercancía se adquiere ${ }^{\text {"ze }}$.

Pero el valor de las mercancias tiene una segunda dimensión. Esta dimensión viene dada por la cantidad de trabajo necesario para su producción. En este caso, es el tiempo de trabajo la medida del valor. Por lo tanto, para nuestro economista existe una doble determinacion del valor de la mercancia: "una que lo define en relación con la cantidad de 
trabajo necesario para su producción, y otra que to encuentra en la cantidad de trabajo vivo con el que la mercancía puede ser comprada, - sea en la cantidad de mercancía con la que puede ser comprada una determinada cantidad de trabajo vivo"27. Existen, pues, dos criterios para la determinación del valor en Smith. Y, como senala Biagio de Giovanni, son dos criterios complementarios al nivel de la producción simple de mercancias. A este nivel, existe "coincidencia entre el tiempo de trabajo necesario y el valor del trabajo: o bien, un criterio equivale al otro y puede ser perfectamente traducido en el otro"ze. Al nivel de la produción simple de mercancias el intercambio se realiza entre una determinada cantidad de trabajo vivo y una cantidad igual de trabajo objetivado, de donde se sigue la coincidencia entre valor del trabajo y tiempo de trabajo ${ }^{20}$.

Ahora bien, una vez que nos ubicamos en el capitalismo, no hay para Adam Smith una coincidencia o equivalencia entre el 'valor del trabajo' y el 'valor del producto del trabajo'. Ello es asi porque "la cantidad de trabajo total necesaria para producir un objeto es mayor que la parte que sirve al trabajador para reconstituir su propio trabajo"so; "cambiando el producto completo por dinero, por trabajo o por cualquier otro objeto -nos dice Smith-, además de cuanto pueda bastar para pagar el precio de los materiales y el salario de los trabajadores, hay que dar algo para el beneficio de quien haya emprendido el trabajo"31. Más aún, "Es evidente que la cantidad adicional (de trabajo) se debe a los beneficios del capital que anticipó los salarios y proporcionó los materiales de aquel trabajo"32.

Adam Smith, pues, pone los ojos en un hecho fundamental de la economía capitalista: la cantidad de trabajo que el obrero invierte en la producción de una mercancias tiene que ser 'mayor' que la necesaria para reconstituir su propio valor, esto es, su salario. En este sentido, la cantidad de trabajo contenida en el 'valor del trabajo' no se iguala a la contenida en el producto del trabajo; el cambio entre los productos del trabajo y el trabajo mismo ya no se da a partir de cantidades equivalentes.

Nuestro autor capta, al menos intuitivamente, el rasgo fundamental y específico de la economía burguesa: "el hecho de que el cambio entre trabajo vivo y mercancia en cuanto capital aparece como cambio entre cantidades desiguales de trabajo... Smith pone en evidencia... el origen de la plusvalía misma, tal y como dicha plusvalia se produce en la relación entre capital y esa particular mercancía que es la fuerza de trabajo"33. Pero Adam Smith sólo capta intuitivamente este mecanismo de explotación que impera en el capitalismo. Es Marx el que logra declifar 
cómo, en la relación capital-trabajo, surge un excedente que es acumulado por los capitalistas y que es el motor y fin de su actividad.

Sin embargo, en la percepción de lo que constituye el secreto de la dinámica económica capitalista Smith es más lúcido que David Ricardo. En efecto, éste asume que lo que rige el intercambio de mercanclas no es el 'valor del trabajo', sino la cantidad de trabajo necesario para su producción. Por tanto, es la cantidad de trabajo invertido en la producción de una mercancia lo que permite determinar su vabr y su equivalencia con otras mercancias. Pero Ricardo no se plantea el problema del intercambio que se opera en el capitalismo entre trabajo vivo y capital. "Aunque (Ricardo)... no puede aceptar la tesis de Smith acaba limitándose a constatar un dato de hecho de la producción capitalista, que el valor del trabajo siempre es menor que el valor del producto del trabajo, sin explicar 'por qué y cómo' sucede, mientras que a este respecto, Smith demuestra la tremenda capacidad para captar en forma problemática un rasgo esencial y específico de la economía capitalista, el hecho de que el cambio entre trabajo vivo y mercancla en cuanto capital, aparece como cambio entre cantidades desiguales de trabajo"34.

Marx enfrenta la tarea de decifrar ese rasgo esencial y especifico de la economia capitalista, esto es, "el hecho de que el cambio entre trabajo vivo y mercancia en cuanto capital, aparece como cambio de cantidades desiguales de trabajo". Y para ello Marx introduce modificaciones sustanciales en la teoria del valor de los economistas clásicos, lo cual da por resultado la formulación de una nueva teoria del valor.

Lo más novedoso de la formulación maxiana consiste en que entiende la capacidad humana de trabajo, el "rabajo vivo", como mercancía: la mercancia fuerza de trabajo. Ciertamente, como pensaban los clásicos, en el capitalismo el trabajo humano es la fuente de todo valor, pero el trabajo humano convertido en mercancla, es decir, convertido en fuerza de trabajo. Ahora bien, esta mercancla es una mercancla sui generis: en su producción y reproducción, incorpora menos horas de trabajo socialmente necesario del que produce cuando es puesta a funcionar. Es decir, la mercancia fuerza de trabajo produce más valor del que ella misma necesita para producirse y reproducirse. Este trabajo excedente es llamado por Marx plusvalía. "El proceso de consumo de la fuerza de trabajo es, al mismo tiempo, el proceso de producción de la mercancia y de la plusvalia... el facto decisivo es el valor de uso específico de esta mercancia, que le permite ser fuente de valor, y de más valor que el que ella misma tiene. He aqui el servicio especifico que de ella espera el capitalista ${ }^{\text {ms }}$.

Por lo tanto, el secreto de la producción burguesa estriba en la re- 
ducción de la capacidad humana de trabajo a mercancla. El mecanismo de explotación específico de esta sociedad radica en la virtualidad propia de la mercancla fuerza de trabajo de generar más valor del que ella misma necesita para producción y reproducción. Ese valor excedente, esa plusvalla, va a parar a manos de los duenos de los medios de producción, es decir, a manos de los capitalistas. Es esta reducción la que posibilita, a su vez, la mercantilización de la totalidad de las relaciones sociales en la sociedad burguesa.

Comprender que la capacidad humana de trabajo es una mercancla más supone para Marx comprender la desigualdad en el intercambio entre 'valor del trabajo' y 'valor del producto del trabajo', ya problematizada por Smith. Esa desigualdad se explica, básicamente, porque la mercancla fuerza de trabajo es una mercancla capaz de generar más valor del que ella misma necesita para reproducirse como tal mercancla. Es decir, el valor de la fuerza de trabajo ('valor del trabajo' = salario) es menor que el valor producido ('valor del producto del trabajo'). La diferencia entre ellos es la plusvalla, o también como dice Marx, el "trabajo impago".

En definitiva, el tratamiento que Marx hace de la problemática del valor le permite superar las limitaciones que se encuentran en el tratamiento del mismo problema efectuado por los clásicos. Marx logra explicar rigurosamente cuál es la raiz de la desigualdad del intercambio entre trabajo y capital vigente en la sociedad burguesa y cuál es la naturaleza de ese valor excedente que va a parar a manos de los capitalistas. Ese valor excedente es la plusvalia y la desigualdad en el intercambio entre valor del trabajo (salario) y el producto del trabajo (valores producidos) se explica por la conversión de la capacidad humana de trabajo en mercancia, es decir, en fuerza de trabajo. Este tratamiento le permite, a su vez, determinar la especificidad del sistema capitalista de producción: en el capitalismo se ha generalizado y universalizado la producción de mercancias, 10 cual ha sido posibilitado por la reducción del trabajo humano a fuerza de trabajo, es decir, a trabajo abstracto ${ }^{36}$.

La indagación de Marx en torno al problema del valor se convierte, asl, en una superación de las reflexiones realizadas por los economlstas burgueses. Como trasfondo de esta superación se encuentra el crlterio histórico propio de la teorización marxiana. Sólo captando al capltalismo como realidad histórica, esto es, transitoria, pudo Manx determlnar su especificidad y su dinámica propia. Como puntualiza M. Blanchl: "la forma de valor asumida por el trabajo (...) es la forma más abstracte, pero también la más general del modo de producción burgués, has- 
ta el punto de constituir su forma peculiar y especifica... sólo con Marx queda claro que la forma del trabajo en abstracto... es en realidad una forma mediata, un punto de llegada histórico determinado por relaciones de producción específicas, y no un dato natural, ni un elemento originario de cualquier relación económicans?.

\section{La critica al orden soclal existente}

Karl Marx fue un gran humanista; es decir, se preocupo, ante todo, por el hombre como individuo humano concreto (A. Schaff). "El interés por el hombre real - nos dice Ota Sik-, por el conocimiento de su condición social y la unidad en la dinámica de esa relación hombresociedad fueron ya desde un principio los intereses subjetivos característicos de Marx, que hasta el final de su vida jamás le abandonaron"38. "Este humanismo de Marx - sehala Roger Garaudy - procede de los análisis que han hecho posible el materialismo histórico y el descubrimiento del papel histórico de la clase obrera, que sólo puede liberarse liberando a toda la sociedad... el humanismo de Marx es la actualización de una posibilidad histórica ${ }^{39}$.

Es desde esta perspectiva humanista que Marx esboza su critica al orden social establecido - al orden social burgués-, la cual apunta hacia dos cuestiones fundamentales. En primer lugar, Marx critica la atomización social que genera el trabajo productor de mercancias, es decir, el trabajo que está en la base de la fetichización de las relaciones sociales burguesas. En segundo lugar, Marx critica la deshumanización provocada por este trabajo productor de mercancias.

\subsection{La atomlzación de la realldad humano-soclal}

La producción de marcancias conduce a la "atomización de la vida social". Es decir, conduce a la oposición y al enfrentamiento de los hombres entre sí. Esto es asi porque, en el sistema de producción burgués, los hombres se comportan como átomos, aislados los unos de los otros, persiguiendo cada uno su propio interés. Sin embargo, el hombre - tal como lo plantea Marx en las "Tesis sobre Feuerbach"es una realidad social: el ser humano no puede realizarse como tal como ser humano integral- si no es en cooperación orgánica con los demás individuos humanos. $Y$ es precisamente este rasgo esencial del hombre - su socialidad intrínseca - el que es violentado por el trabajo privado que impera en el capitalismo. "Los hindividuos no hubieran descendido nunca a tales abismos si en la práctica su aislamiento mutuo no fuera, como lo es, total... Los hombres no se conocen a si mismos y a los demás como seres sociales cuyas necesidades requieren la coo- 
peración mutua, sino como entidades particulares antagónicas: una galaxia anárquica de mundos egolstas"

Los hombires, pues, se enfrentan antagónicamente unos a otros, se mueven atomisticamente. En la ralz de esta atomización de la vida social se encuentra, según Marx, el trabajo productor de mercanclas; en consecuencia, se encuentra la forma fetichizada que adquieren los productos del trabajo cuando se convierten en mercanclas. La producción generalizada de mercanclas $-y$ el fetichismo que les es instrínsecoconduce a la reducción de los individuos a "individuos privados"; esa reducción conduce al "ocultamiento" del nexo social que, pese a todo, los individuos mantienen entre sl. "En el modo de producción capitalista, la forma fetichista adquirida por los productos del trabajo humano oculta, como categorla económica, el sustrato social real constituido por las relaciones entre los individuos, reducidos al papel de propietarios privados y al de mercaderes" ${ }^{14}$.

Y Marx nos aclara cuál es la raiz de esa reducción de las relaciones sociales a relaciones entre individuos privados:"La conducta puramente atomistica de los hombres en su proceso social de producción, y, por tanto, la forma material que revisten sus propias relaciones de producción, sustraldas a su control y a sus actos individuales conscientes, se revelan ante todo en el hecho de que los productos de su trabajo revisten, con carácter general, forma de mercancla'a'. Justamente, el trabajo privado - el trabajo productor de mercanclas - es un trabajo que, al enfrentar antagónicamente a los hombres entre sl, desnaturaliza el nexo social que los vincula y unifica como humanidad. Es decir, al trabajo privado introduce una "ruptura" en las relaciones humano-sociales. Las clases sociales no son más que la expresión macro-social de esta oposición radical entre los hombres que se vive ya en el mismo proceso de producción. Ya en la génesis del modo de producción burgués se pertila este enfrentamiento de clases: "El régimen del capital -dice Marx - presupone el divorcio entre los obreros y la propiedad sobre las condiciones de realización de su trabajo... Por tanto el proceso que engendra el capitalismo sólo puede ser uno: el proceso de disociación entre el obrero y la propiedad sobre las condiciones de su trabajo... La llamada acumulación originaria no es, pues, más que el proceso historico de disociación entre el productor y los medios de producción ${ }^{\text {4a3. }}$.

La dinámica histórica del capitalismo genera, pues, un enfrentamiento irreconciliable entre la clase obrera y la clase burguesa, es decir, entre la clase "disociada" de los medios de producción y la clase poseedora de esas condiciones de producción. En opinión de Marx, el antagonismo entre estas clase es total; es, asimismo, un antagonismo es- 
tructural: es un antagonismo que tiene sus raices en la búsqueda insaciable de plusvalía por parte del capitalista y en la resistencia que opone -primero instintivamente $y$, después, conscientemente- el obrero.

"Por instinto -senala Rubel-, el obrero sabe que proporciona al capitalista un excedente de trabajo, un producto por el que no recibe nada a cambio, pero ignora el grado exacto en que es explotado; en otros términos, desconoce la relación entre el trabajo necesario y el excedente, puesto que uno y otro son realizados en la misma jornada de trabajo. Su resistencia a la prolongación de la jornada de trabajo es la expresión de esta certidumbre. El capitalista, cuya sed de ganancia jamás llega a saciarse, evoca las leyes del intercambio de mercanclas al intentar obtener el máximo de beneficio representado por la mercancláa-trabajo"m.

Al capitalismo le es intrínseca la lucha y el conflicto. Esta conflictividad estructural no se reduce a ser algo meramente socio-económico, sino que tiene dimensiones antropológicas importantes. En efecto, el enfrentamiento radical entre las clases abre una fisura estructural en la misma socialidad humana. Más aún, si el hombre es "el conjunto de sus relaciones sociales", ese enfrentamiento se convierte en una amenaza para la misma naturaleza humana.

Esa fisura estructural se expresa bien en to que Marx llama "atomismo social". Este atomismo no es otra cosa que el "aislamiento mutuo total entre los hombres", es el enfrentamiento de ellos como "entidades particulares antagónicas". La lucha de clases es justamente la expresión más acabada de este atomismo social; de esta atomización de las relaciones sociales. Por otra parte, dicha fisura estructural se hace sentir inexorablemente en la vida de los individuos humanos concretos. Estos se comportan atomísticamente, buscando su interés puramente individual sin importarles to que sucede con el conjunto de la sociedad. Es decir, "La indiferencia o la franca hostilidad que caracterizan las relaciones entre los obreros y los capitalistas tienen su equivalente en toda la sociedad. Nadie reconoce las necesidades de los demás o el papel que los demás pueden cumplir en la satisfacción de sus propias necesidades. ... el individuo egoista que vive en el capitalismo se ha reducido hasta alcanzar el tamano de un átomo, o sea un ser desconocido, autónomo, carente de anhelos, absolutamente pleno, un ser bendito' ... Los fragmentos de lo que significa ser un hombre... se han disgregado por doquier y su unidad se ha perdido hasta tal punto que ya es irreconciliable"45.

Marx condena este atomismo social que, en el capitalismo, atraviesa 
al conjunto de la sociedad y la totalidad de la personalidad humana. A esta atomización de las relaciones sociales y la personalidad humana, Marx opondrá la socialidad plena y constitutiva de ambas. Una soclalidad que para él habrá de ser conquistada históricamente mediante la actividad práctico-revolucionaria de los hombres. En definitiva: "Cuando más lejos nos remontamos en la historia, tanto más aparece el individuo... como dependiente y formando parte de un todo mayor: en primer lugar y de una manera muy enteramente natural, de la familia y de esa familia ampliada que es la tribu; más tarde, de las comunidades en sus distintas formas... El hombre es, en el sentido más literal, un zoon politikón, no solamente un animal social, sino animal que sólo puede individualizarse en la sociedad. La producción por parte de un individuo aislado, fuera de la sociedad... no es menos absurda que la idea de un desarrollo del lenguaje sin individuos que vivan juntos y hablen entre si ${ }^{46}$.

Marx, pues, reivindica teórica y prácticamente la socialidad instrínsecas tanto de la vida personal como de la vida social. La primera crítica marxiana al orden social establecido apunta en esta dirección: es una crítica a la atomización de las relaciones sociales y la vida individual del hombre generada por la dinámica del modo de producción capitalista. Marx - ya lo dijimos antes - esboza una segunda crítica al orden social existente: la deshumanización a que conduce el trabajo productor de mercancias.

\subsection{Producclón de mercanclas y deshumanización}

Ante todo, el trabajo productor de mercancias -el trabajo que atomiza la vida individual y social- deshumaniza al hombre porque le imposibilita ejercer en forma plena su capacidad de trabajo. Es decir, le imposibilita realizarse plenamente como ser de la praxis, esto es, como un ser que, al transformar la realidad natural y social, se transforma a sí mismo, asimilando e incorporando a su propia realidad las potencialidades de la realidad exterio ${ }^{77}$. El trabajo, en su sentido más pleno, es la forma radical que tiene el hombre de enfrentarse con la realidad y transformarla. Por consiguiente, el trabajo - la praxis productiva- es la condición eterna de la vida humana; el trabajo es lo que define al hombre como tal.

Ahora bien, el individuo humano originariamente ejerce su praxis productiva desde y a través del control de sus condiciones de producción. Es decir, desde y a través del control de los medios y el objeto de trabajo ${ }^{48}$. Sin embargo, en la sociedad burguesa los productores no ejercen un mínimo control sobre sus condiciones de producción. $Y$ ello 
porque esas condiciones de producción han sido apropiadas privadamente por los capitalistas. En consecuencia, al no controlar sus condiciones de producción, los trabajadores no controlan sus proplas producciones $y$, peor aún, no controlan ni su propia capacidad productiva. Estas producciones y esa capacidad productiva pertenecen al empresario capitalista. De aquí, pues, que los trabajadores no puedan ejercer a plenitud ese "intercambio de materias con la naturaleza" del que habla Marx en El Capital, y que es justamente el que posibilita la transformación de la naturaleza extema y, con ello, el desarrollo de las potencialidades internas humanas.

En el capitalismo se opera una ruptura en el proceso de trabajo: las condiciones materiales del proceso de producción se han separado totalmente de la actividad humana productiva; esta actividad humana productiva sólo se relaciona con estas condiciones de producción -asl como con su producto- de una forma externa. La propiedad privada capitalista sobre los medios de producción rompe la unidad orgánica del proceso humano de trabajo: la unidad orgánica existente entre los medios de trabajo, el objeto y la actividad productiva. La unidad armónica de estos elementos es una conditio sine qua non para que el hombre se realice a cabalidad; su ruptura es una amenaza para esta realización y humanización del hombre.

En la sociedad burguesa, pues, los hombres no pueden reallzar plenamente esa facultad que los diferencia radicalmente del resto de los animales: su capacidad de trabajo. Ciertamente, que en el capitalismo los hombres trabajan, pero su trabajo no está en función de su realización humana plena. Ese trabajo está en función de la clase poseedora de los medios de producción; es decir, es un trabajo que no pertenece al trabajador, sino que pertenece al capitalista. Este, al apropiarse de las condiciones materiales de producción, puede apropiarse -y se apropia de hecho- de la capacidad humana de trabajo y sus productos. Esta es la raiz de la alienación y enajenación total que padecen los hombres en la sociedad burguesa.

La crítica de Marx, en este punto, está encaminada a poner en evidencia los obstáculos insalvables que impone el sistema de producción burgués al ejercicio pleno y total de la capacidad humana de trabajo $y$, por tanto, los obstáculos que impone a la realización del hombre como ser de la praxis ${ }^{40}$.

Sin embargo, la deshumanización provocada por la dinámica y funcionamiento del sistema capitalista no se agota en este aspecto que hemos sehalado. Marx enfrenta críticamente otro fenómeno de deshumanización provocado por el trabajo productor de mercancias: la desin- 
tegración de la personalidad de los trabajadores.

En efecto, el trabajo productor de mercancias imposibilita al obrero el desarrollo y expansión de sus potencias interiores. La razón de ello estriba en que en el proceso de producción capitalista el trabajador se ve forzado a reducir su capacidad de trabajo a una actividad simple y mecanizada. $Y$ ello porque sólo reduciendo la actividad productiva a una serie de actividades simples es factible "medir" esa capacidad de trabajo; sólo así es factible su conversión en mercancia. La división del trabajo hace posible esta simplificación y especialización: "Por tanto, la reducción del trabajo individual al trabajo general humano corresponde a relaciones sociales determinadas, contraidas por los hombres sometidos a las exigencias de un sistema productivo dotado de condiciones de funcionamiento especificas. La más importante de estas exigencias es una división del trabajo llevado al extremo que establece una infinita variedad de actividades útiles, desde la más simple hasta la más compleja. La forma de mercancia que adoptan los productos humanos supone la reducción del trabajo complejo y calificado al trabajo simple, medido por el 'voltaje del péndulo"'so.

Esta reducción del trabajo humano complejo a "trabajo simple" acarrea inevitablemente consecuencias deshumanizadoras para el obrero. Esta deshumanización se hace sentir, ante todo, en el embrutecimiento que sufre el trabajador al someterse a la dinámica cuantitativa que rige el proceso de producción burgués. Esta dinámica hace que el trabajador sea "menos todavia que una bestia de carga". "Físicamente destrozado y espiritualmente embrutecido, es una simple máquina para producir riqueza ajena... toda la historia de la moderna industria demuestra que el capital, si no se le pone freno, laborará siempre, implacablemente y sin miramientos, por reducir a toda la clase obrera a este nivel de la más baja degradación" ${ }^{\prime 51}$. La inserción del trabajador en el engranaje de producción capitalista lo deshumaniza totalmente; es decir, lo deshumaniza física y espiritualmente. Fisicamente, porque el trabajador se ve obligado a "absorver" su vida en el trabajo para el capitalista, quien utiliza el "trabajo vivo" hasta su agotamiento físico52. Espiritualmente, porque el trabajador ya por el mero hecho de llevar su actividad fisica hasta los limites de sus resistencia tiene bloqueadas las posibilidades de que crecimiento y desarrollo espiritual ${ }^{53}$. Es decir, en el proceso de produción capitalista el trabajador no se puede realizar como una realidad total e integral. "Si nos detenemos a analizar de cerca y en detalle este proceso, veremos ante todo que el obrero, reducido a ejecutar de por vida la misma operación, acaba por ver convertido todo su organismo en órgano automático y limitado de esa operación, lo cual hace que necesite, para ejecutarla, menos tiempo que el oficlal 
obligado a ejecutar por turno toda una serie de operaciones distintas. El obrero total combinado que forma el organismo viviente de la manufactura es, en realidad, una suma de obreros parciales y limitados de ese tipo"ss. Marx también habla en El Capital de la "depauperización moral" y "degeneración intelectual" que sufre el hombre al convertirse en una "simple máquina para la fabricación de plusvalia"ss.

En definitiva, Marx revela críticamente la amenazas y peligros que sobre la humanidad misma de los hombres hace sentir la dinámica socio-económica capitalista: desarrollo extremo y total de la enajenación, por la universalización y generalización de la producción de mercancias; imposibilidad para el hombre de ejercer su capacidad práxicoproductiva en forma plena; agotamiento físico extremo de los trabajadores y deformación de su personalidad; y atomización de las relaciones sociales y la vida individual ${ }^{56}$. Marx, al revelar en su obra de madurez especialmente en los Grundrisse y El Capital estos efectos deshumanizadores del capitalismo, postula la necesidad de su transformación; es decir, propone un proyecto de transformación históricosocial del orden establecido, en el que se reivindique la socialidad de la humanidad, el despliegue total de la personalidad humana y la unidad orgánica del hombre con sus condiciones de producción.

\section{El proyecto de transformación histórlco-soclal}

Como ya lo indicábamos, el análisis marxiano de la dinámica económica capitalista y la crítica a su funcionamiento deshumanizador tienen como finalidad última contribuir a la transformación estructural del orden social burgués. Es decir, el planteamiento de Marx es, al mismo tiempo que análisis y crítica del capitalismo, una propuesta para su superación radical. Esta propuesta supone una serie de condiciones o premisas y apunta hacia la instauración de un nuevo orden social y humano. ¿Cuáles son esas condiciones o premisas? ¿Hacia dónde apunta la transformación del capitalismo propuesta por Marx?

\subsection{Las condiciones de transformación del capltallsmo}

Ante todo, para Marx la superación radical del capitalismo tiene como base objetiva y real la propia dinámica que lo rige. Es decir, el propio sistema presenta tendencias estructurales que hacen necesaria su transformación. ¿Cuál es la raíz de estas tendencias?

La raiz objetiva que fundamenta y posibilita la transformación estructural del orden social burgués es la contradicción irresoluble entre las fuerzas productivas -cada vez más desarrolladas en la línea de la socialización- y las relaciones sociales de cartacter privado que domi- 
nan el conjunto de la vida social y económica. Como dice Marx: "el régimen capitalista se nos presenta, de una parte, como una necesidad histórica para la transformación del proceso de trabajo como un proceso social, de otra parte esta forma social del proceso de trabajo aparece como un método empleado por el capital para explotarlo con más provecho, intensificando su su fuerza productiva"57. Ahora bien, esta dinámica socializadora de las fuerzas de produccion choca contradictoriamente con la forma privada de apropiación en función de la cual está esa socialización. Más aún, esas formas de apropiación privada -tantio de las condiciones de producción como de los productos del trabajo de los obreros- se convierten en un freno, en una traba, al desarrollo de las fuerzas de producción; mientras que éstas exigen, a medida que se desarrollan, una socialización más total, las formas de apropiación privada impiden esa socialización, que evidentemente es contraria a la logica de la acumulación burguesa.

En el capitalismo, "La cooperación de obreros asalariados tiene, como condición material la concentración de grandes masas de medios de produccion en manos de cada capitalista, el alcance de la cooperación o la escala de la producción depende del grado de concentración de estos elementos"so. Es esa "concentración de grandes masas de medios de producción en manos de cada capitalista" la que, a medida que se desarrolla y complejiza la dinámica productiva, entra en contradicción con la "cooperación entre los obreros" y el proceso de socialización hacia el cual apunta la dinámica de producción burguesa. Como resume Mandel: "Dadas las contradicciones del modo de produccion capitalista pueden asumirse en la contradicción general y fundamental: la contradicción entre la socialización efectiva de la producción y la forma privada, capitalista, de la apropiación ${ }^{\prime 60}$.

Esta contradicción -general y fundamental, como dice Mandeles la que está en la base de las tendencias reales que presenta el capitalismo en la línea de su transformación radical. Como ya vimos antes, esta contradicción tiene su expresión clásica en las llamadas "crisis de sobreproducción", es decir, en las crisis generadas por la superabundancia de mercancias que no encuentran consumidores, dada la estrechez de las formas de apropiación y consumo. Justamente, este desfase existente entre producción y consumo trae como resultado un "quiebre" en la lógica de producción burguesa. Esto es, el capitalista no puede embolsarse su cuota de plusvalía si no es vendiendo la totalidad de sus mercancias. En la venta, el capitalista realiza su plusvalía. "EI excedente (surplus) no surge de la circulación, tan sólo en ella se realiza... El capital es la unidad inmediata del producto y el dinero, o mejor entre la producción y lá circulación'so. 
La Kógica de las relaciones sociales burguesas conduce a un "quiebre" en esta unidad entre producción y circulación, es decir, entre el trabajo impago obtenido en el proceso de producción y su realizaclón efectiva en la circulación.

La capacidad de consumo de la sociedad - escribe Marx-, "no se halla determinada ni por la capacidad productiva absoluta ni por la capacidad absoluta de consumo, sino por la capacidad de consumo a base de las condiciones antagónicas de distribución que reducen el consumo de la gran masa de la sociedad a un m/nimo susceptible solo de variación dentro de límites muy estrechos. Se halla limitada, además, por el impulso de acumulación, por la tendencia a acrecentar el capltal y a producir plusvalia en una escala ampliada. Es ésta una ley de la producción capitalista, ley que obedece a las constantes revoluclones operadas en los propios métodos de producción... La contradicclon Interna tiende a compensarse mediante la expansión del campo externo de la producción. Pero cuando más se desarrolla la capacidad productiva, más choca con la angosta sobre la que descansan las condiciones del consumo"si.

El sistema capitalista se apoya, pues, en una "base contradictoria": el desfase y el antagonismo entre las fuerzas de producción y las relaciones sociales. Este desfase y antagonismo conduce inexorablemente a las crisis: "Estas se hacen frecuentes y más violentas, ya por el solo hecho de que, a medida que crece la masa de producción y, por tanto, la necesidad de mercados más extensos, el mercado mundial va reduciéndose cada vez más y más... Pero el capital no vive sólo del trabajo... Este amo, a la par distinguido y bérbaro arrastra consigo a la tumba los cadáveres de sus esclavos, hecatombes enteras de obreros que sucumben en las crisis" 82 . En el fondo de esta "base contradictoria" que fundamenta al sistema de producción capitalista se encuentra, sin embargo, una contradicción mucho más radical: la contradicción entre el trabajo humano y el capital63. Bajo el capitalismo, trabajo y capital forman una unidad contradictoria; una unidad en la que cada uno de los términos es presupuesto y negación del otro: "de un lado está el capital $y$ del otro el trabajo, ambos como figuras autónomas y en contradicción", ambos, pues, como reciprocamente ajenos"er.

"El trabajo vivo, el trabajador mismo como otro que el capital, que el capital mismo; la clase trabajadora como otra que la clase capitalista... El otro, sensible, que Feuerbach había descubierto en la relación yotú... es aplicado por Marx al trabajador, al otro que el capital, cuya 'objetividad coincide con su inmediata corporalidad (...)', camalidad, con su piel; la piel que vende la prostituta para comer, la piel que es objeto del 
sadismo del torturador por represión política, la piel del trabajador herida y mutilada por el plustrabajo futuro. Esta piel del otro es todavia exterior al capital, como to 'absolutamente contradictorio"st.

En esencia, pues, el capital es la negación del trabajo y del trabajador; es decir, el capital se opone al desarrollo pleno de las potencialidades del trabajo humano. El limite estructural del capitalismo son sus relaciones sociales, que imponen obstáculos insalvables al desarrollo de las fuerzas productivas y al desarrollo de la humanidad. "El verdadero límite de la producción capitalista es el mismo capital; es el hecho de que, en ella, son el capital y su propia valorización lo que constituye el punto de partida y la meta, el motivo y el fin de la producción; el hecho de que aqui la producción sólo es producción para el capital y no, a la inversa, los medios de producción simples medios para ampliar cada vez más la estructura del proceso de vida de la sociedad de los productores" ${ }^{65}$. Justamente por ello, "si el régimen capitalista de producción constituye un medio histórico para desarrollar la capacidad productiva material y crear un mercado mundial correspondiente, envuelve el propio tiempo una contradicción constante entre esta misión histórica y las condiciones sociales de producción propias de este régimen"se.

Desde la obra de madurez de Marx, la trasformación del capitalismo es una exigencia intrinseca de su dinámica histórica. Dicho de otra forma: "Más allá de determinado punto, el desarrollo de las fuerzas productivas dentro del capitalismo no funciona. En este punto se manifiesta la necesidad económica del hundimiento del capitalismo, asl como, en su tiempo, el hundimiento de los modos de producción anteriores fue una necesidad"87. Precisamente, este agotamiento estructural del sistema capitalista halla su expresión más grave en las crisis de sobreproducción, que son las "crisis que surgen necesariamente del capital en sises.

Lo anterior no significa que el hundimiento del capitalismo sea algo mecánico; es decir, que la contradicción fuerzas productivas-relaciones sociales conduzca por si misma al "dernumbre" del capitalismo. Para Marx, to que manifiesta esa contradicción - sobre todo cuando estalla en forma de crisis - es la necesidad estructural de transformación que como tendencia plantea la propia dinámica económico-social burguesa. "Abandonadas a su propio determinismo, esas leyes deben provocar el dernumbe de la civilización técnica y la desaparición de toda cultura humana... No obstante, esas 'leyes inmanentes' no son más que formulaciones abstractas, cient/ficamente establecidas con el fin de tomar en cuenta las tendencias e impulsos ciegos que actúan en el fondo de la sociedad capitalista: los hombres no sólo pueden cambiarlas sino también adueharse de ellas' ${ }^{\prime 60}$. 
Son precisamente esas "tendencias e impulsos ciegos" los que constituyen las condiciones objetivas de la transformación de la sociedad burguesa. Son esas condiciones objetivas las que exigen, como un momento decisivo del cambio estructural efectivo, la participación consciente de la clase que es pieza fundamental para el funcionamiento económico de la sociedad burguesa y para la construcción de la nueva sociedad: la clase obrera. El movimiento obrero introduce las condiciones subjetivas necesarias para hacer efectivo el cambio revolucionarlo de la sociedad.

Como escribe Cerroni: "Si para Marx el capital es una relación (juna relación social!) que comprende tanto al capital como la fuerza de trabajo, el destino del capital no puede no estar condicionado por el nivel de desarrollo de la misma fuerza de trabajo, nivel que llega a englobar las típicas connotaciones subjetivas de la fuerza de trabajo en su conjunto que están constituidas por el grado de su organización, de su resistencia, de su consciencia: en definitiva, por la relación absolutamente política que se instaura entre la totalidad del sistema social y la parte constitutiva que representa su antitesis económica y, más en general, histórica. Cualquier otra interpretación conduciria a conclusiones mecanicistas no sólo en la teoría sino también en la teoría política de Marx ${ }^{m 70}$.

En efecto, es la clase obrera la clase llamada a romper la bógica estructural del capitalismo desde y por la asumpción de sus contradicciones. Puede observarse -dice H. Grossman- "que si bien bajo determinadas circunstancias el derrumbe del capitalismo resulta objetivamente necesario... ello no significa que habrá de arribarse a dicho momento 'por si mismo', automáticamente, y que por tanto no queda sino esperar pasivamente. Su irrupción en realidad, y dentro de ciertos limites, está sujeta a la influencia de enfrentamientos conscientes de las dos clases consideradas... De aqui se desprende que el pensamiento que concibe el derrumbe como necesario, como producto de ciertas condiciones objetivas, no está de ningún modo en contradicción con la lucha de clases. Se pone de manifiesto, en cambio, que el derrumbe, a pesar de su inevitable necesidad objetiva, está sujeto en gran medida a la influencia ejercida por las fuerzas vivas de las clases en pugna, otorgando de este modo un cierto margen a la perticipación activa de las clases ${ }^{\text {"71 }}$.

Son precisamente las clases las que, en su lucha, resuelven en una dirección u otra la crisis estructural y las tendencias objetivas del sistema. Es decir, en este proceso contradictorio del devenir capitalista "tenemos como final la lucha de clases, resolviéndose alli el movimien- 
to y la disolución de toda esta basura"7z. En esta lucha, el proletariado debe esforzarse por "emplear sus fuerzas organizadas como palanca para la emancipación definitiva de la clase obrera; es decir, para la aboliclón definitiva del sistema de trabajo asalariado"rs, mediante la toma del poder político de la sociedad.

En resumen, como senala Grossman: "La lucha de la clase obrera por sus reivindicaciones cotidianas se vincula asl con su lucha por el objetivo final". Este objetivo final no es "un ideal introducido desde "el exterior' en el movimiento obrero, cuya concreción es independiente de las luchas del presente, puesto que permanece reservado para un futuro lejano, sino que consiste, tal como lo indica la ley del dernumbe puesta aqul de manifiesto, en el resultado producido por la lucha de clases inmediata de todos los días, y cuya materialización se acelera por estas luchas"74.

¿Cuál es el 'objetivo final' al que deben apuntar las luchas de la clase obrera? ¿Cuáles son los pasos concretos que deben darse para alcanzar ese 'objetivo final'? Esto es lo que veremos a continuación.

\subsection{La 'utopla' del proyecto de transformación: el 'reino de la llbertad'}

El 'objetivo final' de la lucha de la clase obrera, para Marx, no es otro que la instauración de un nuevo orden social, fundado en un nuevo modo de producción. Este nuevo modo de producción habrá de caracterizarse por rescatar y potenciar la dimensión social, comunitaria, del trabajo humano. En otras palabras, el nuevo orden habrá de ser un orden social plenamente socializado. Esta socialización plena tendrá como base el control total que los individuos asociados ejercerán sobre las condiciones y el proceso de producción. Marx describe asl ese nuevo orden: "La libre individualidad, fundada en el desarrollo universal de los individuos y en la subordinación de su productividad comunitaria (...), social, como patrimonio social, constituye el tercer estadio (del desarrollo social)... La producción social... está subordinada a los individuos y controlada comunitariamente (...) por ellos como un patrimonio... (Es un) libre cambio entre individuos asociados sobre el fundamento de la apropiacion y del control comunitario de los medios de producción. Esta última asociación no tiene nada de arbitrario: ella presupone el desarrollo de condiciones materiales y espirituales"75.

El nuevo modo de organización social en el que se superan las contradicciones del viejo orden- supone el desarrollo histórico-soclal generado por el capitalismo. El sistema capitalista de producclón se convierte $\rightarrow$ por la calidad y la cantidad de las fuerzas productlvas que 
libera - en la condición de posibilidad de la nueva sociedad. La prueba fehaciente de ello se encuentra en la socialización del proceso productivo exigida por la dinámica económica burguesa. En esta socialización de la producción, el capitalismo anuncia ya, en germen, el carácter $\infty$ munitario y plenamente socializado de la nueva sociedad. "La socialidad del proceso de trabajo que ha tenido lugar objetivamente en el capitalismo debe romper el vínculo privado de la apropiación del trabajo ajeno para alcanzar una socialidad subjetiva de las mismas relaciones de producción $n^{m e}$.

El capitalismo, "al crear nuevas fuerzas productivas en un grado hasta entonces desconocido" y al posibilitar una "organización social del trabajo"n crea las condiciones sobre las que se edificará el nuevo orden social. En el mismo, imperarán unas relaciones sociales de indole comunitario, acordes y en consonancia con la naturaleza del proceso de producción.

Por otra parte, la socialización de los medios y las condiciones de producción conducirá a la superación del fetichismo, ya que la misma implica y supone el disfrute de los productos del trabajo por parte de los productores directos y la "ransparencia" del proceso social mismo, asl como el desarrollo de una consciencia plena sobre lo que se es y sobre lo que se hace. La dominación y el sometimiento humano por los fetiches se supera mediante "una asociación de hombres libres que trabajen con medios colectivos de produccion y que desplieguen sus numerosas fuerzas individuales del trabajo, con plena consciencia de to que hacen, como una gran fuerza de trabajo social. En esta sociedad se repetirán todas las normas que presiden el trabajo de un Robinsón. pero con un carácter social y no individual. Los productos de Robinsón eran todos producto personal y exclusivo suyo, y por tanto objetos destinados a su uso. El producto colectivo de la asociación a que nos referimos es un producto social"pr.

En la base de este proceso de socialización de la totalidad de la vida social se encuentra la abolición de las formas privadas de apropiación que imperan en la sociedad burguesa y sus sustitución por unas relaciones de apropiación de carácter social. Es decir, la instauración de una sociedad plenamente socializada implica y supone la abolición de las formas de propiedad privada vigentes en el capitalismo. Sólo asl, las nuevas relaciones sociales se convertirán en un momento fundamental para la superación de la fetichización y cosificación de las relaciones sociales: "aqui -dice Marx - las relaciones sociales de los hombres con su trabajo y los productos de su trabajo son perfectamente claras y sencillas, tanto en lo tocante a la producción como en lo 
que se refiere a la distribución $n^{-70}$. De este modo, el fetichismo desaparece; desaparece el "halo mistlco" del "proceso social de producción" porque el mismo es "obra de hombres libremente asociados", es decir, ha sido puesto bajo su "mando consciente y racional" tamente, para alcanzar este estadio socio-histórico la sociedad "necesitará contar con una base material o con una serie de condiciones materiales de existencia, que, son, a su vez, fruto natural de una larga y penosa evolución"mi.

Al abolir las relaciones sociales de carácter privado que imperan en el capitalismo y al abolir, con ello, la propiedad privada burguesa, el proletariado se enfrenta con la tarea de abolir la división del trabajo en la que se sostienen las relaciones de propiedad capitalistas. Es decir, en la nueva organización social se debe operar una reestructuración de la división social del trabajo; una división del trabajo controlada socialmente y en función no de la producción de valores de cambio, sino en función de la satisfaccion de las necesidades de la sociedad. "En lugar de una división del trabajo, que se genera necesariamente en el intercambio de valores de cambio, se tendrá una organización (...) del trabajo que tiene como consecuencia la porción que corresponde al individuo en el consumo comunitario (...). (En este) caso el carácter social de la producción es presupuesto, y la participación en el mundo de los productos (...), en el consumo, no es mediada por el cambio de productos de trabajo o de trabajos reciprocamente dependientes"

La instauración de un orden social plenamente socializado, pues, arranca del control comunitario por parte de los individuos agentes los trabajadores- de sus condiciones de produccion y reproducción, asl como de los productos de su trabajo. Este control sobre el conjunto de la vida económico-social se edifica desde la supresión de la propiedad privada burguesa y la división del trabajo que le sirve de soporte. En resumen, "En esta 'producción comunitaria' (...) los trabajadores no sólo tendrian una apropiación comunitaria de los medios de producción, sino el pleno control con consciencia del proceso total de la misma producción $n^{\text {mes. }}$.

También la realización del nuevo orden exige y supone, a la vez que la eliminación de las relaciones de propiedad y la división del trabajo capitalistas, la abolicion de las clases sociales. Esta es una posibilidad histórica que ya se prefigura en el propio orden burgués: "El modo de producción capitalista, por el prodigioso desarrollo que asegura a las fuerzas productivas, crea por primera vez en la historia las condiciones económicas necesarias para la supresión total de la sociedad de clases" $^{\text {nes }}$. Ahora bien, esa posibilidad histórica sólo puede ser reall- 
zada efectivamente en la nueva sociedad a construir por la clase proletaria: la "clase que adquiere un mayor interés por la supresión de toda forma de propiedad privada de los medios de producción, puesto que ella no posee ninguno", clase que "reune en sus manos todas las funciones productivas de la sociedad moderna"es.

Con la abolición de las clases, el proletariado crea las bases para el despliegue total de la personalidad humana, es decir, para la expansión integral de la socialidad e individualidad de los hombres. Se consigue, pues, un desarrollo de los individuos como "individuos universalmente desarrollados cuyas relaciones sociales en cuanto relaciones propias y comunitarias están ya sometidas a su propio control (...) comunitario'es.

En resumen, "La lucha de clases del proletariado moderno se desarrolla entonces en movimiento político, movimiento para la supresión de la propiedad capitalista, para la socialización de los medios de producción y de cambio, para el advenimiento de la sociedad socialista sin clases"87. El fin de este movimiento es la instauración de una sociedad plenamente socializada y transparente - no fetichizada-, en la que los individuos ejerzan un control total sobre sus condiciones de produccion y sobre los productos de su trabajo; es decir, una sociedad en la que los individuos desarrollen su "libre individualidad" y alcancen un crecimiento integral y "universal" de su personalidad.

El análisis y la crítica que hace Marx del orden económico-social burgués le conducen a esbozar un proyecto para su transformación radical. Tal como hemos visto, dicho proyecto tiene como base objetiva la dinámica contradictoria de las fuerzas productivas y las relaciones sociales burguesas. Esta dinámica contradictoria "no es más que la misma necesaria e inevitable contradicción inherente a la subsunción del trabajo por el capital, o sea, el poder existir en cuanto fuerza productiva, sólo en la forma de trabajo asalariado, de trabajo alienado"se. Asimismo, la propuesta de Marx apunta hacia la instauración de una sociedad plenamente humanizada, es decir, una sociedad que sea en todos los órdenes un "reino de la libertad": una sociedad en la que se haya puesto fin al "trabajo impuesto por la necesidad y la finalidad exterior"es. Este "reino de la libertad" es el "horizonte utópico" del proyecto de transformación que Marx va esbozando a lo largo de su vida y que encuentra su formulación definitiva en sus escritos de madurez.

Este proyecto de transformación histórico-social exige la participación consciente y crítica de la clase obrera. Es decir, la clase obrera "está llamada a desempenar un papel histórico ya no corporativo, sino universal... (en) la superación revolucionaria de las relaciones capitalistas de producción, para la completa y definitiva emancipación del 
hombre respecto de las relaciones de producción 'alienantes', cuya culminación encontramos en el capitalismo"so.

La perspectiva de la transformación revolucionaria del orden establecido es, pues, un componente esencial de la obra teórico-política de Marx. Es una perspectiva que está presente tanto en su obra de juventud como en su obra de madurez. "La alternativa revolucionaria... está siempre presente en el análisis científico de Marx, y constituye incluso su misma sustancia... La 'teoría' debe plantearse, para Marx, como ideologia revolucionaria. No es la asunción neutra de la realidad como tal, sino el análisis de la realidad desde el punto de vista de la clase obrera" 91 . Esta teoría, esa "reconstrucción analítica del modo en que funciona el mecanismo de producción capitalista" ${ }^{\prime \theta}$ ) debe resolverse en una práctica revolucionaria, no debe ser un "mero ideal abstracto o propaganda voluntarista y espontánea, sino interpretación científica de la vida económica actual y sus contradicciones'ss. El sujeto de esa práctica revolucionaria es el "proletariado moderno, la clase obrera"en.

En definitiva, el discurso revolucionario de Marx busca fundamentar una práctica que conduzca al establecimiento de un orden socio-histórico auténticamente humano. Para Marx, "Se trata de suprimir lo que fue el principio histórico y sigue siendo el resultado contínuo del capitalismo: la 'separación' entre fuerza de trabajo y condiciones de trabajo'. Sólo entonces el proceso de trabajo volverá a ser como era originariamente en la indistinta comunidad primitiva, auténtico proceso de elaboración humana de la naturaleza en forma social y para satisfacer las necesidades humanas. Pero será un retomo, sin embargo, sobre la base de la riqueza histórica acumulada por el género humano tanto en cuanto a los instrumentos de trabajo como en cuanto a la articulación individual-personal de la comunidad, como, en fin, en cuanto al reconocimiento consciente de la circularidad humana de las actividades individuales, intelectuales y prácticas" 95 . Este es, pues, el "horizonte utópico" del maxismo: el comunismo, es decir, el orden socio-histórico futuro, nunca alcanzable definitivamente, pero siempre presente en las luchas emancipadoras de los trabajadores, esto es, en las luchas emprendidas para superar desde sus raíces el orden histórico existente.

\section{Conclusiones}

Que la elaboración maxiana tiene limitaciones importantes, tanto a nivel dẹl análisis científico como a nivel de la crítica humanista y del proyecto de tranformación, es algo que pocos todavía ponen en duda, sobre todo si se toma como marco de referencia la situación del primer mundo capitalista y la más reciente experiencia vivida por los "soclallsmos reales". 
Pero también, con sus limitaciones, la obra de Maxx sigue siendo muy lluminadora en América Latina. La explotación rapaz y la deshumanización extrema siguen siendo realidades cotidianas en el subcontinente. $Y$ ello no por falta, o carencia de capitalismo, como quieren con M. Novak a la cabeza- los neoconservadores norteamericanos ${ }^{\infty}$, sino como resultado precisamente del sometimiento de nuestra realidad histórica a la lógica y la civilización del capital (I. Ellacuria). Asimismo, en América Latina sigue presente y actuante la utopla y la esperanza, que exigen y necesitan -para no perderse en el idealismo escapista o en el voluntarismo dogmático- un horizonte que realmente apunte hacia la liberación.

Por otra parte, no se trata en esta conclusión de repetir lo que a lo largo de estas páginas hemos venido tratando. Más bien, de lo que se trata es de reflexionar qué forma la elaboración maxiana, entendida como filosoffa de la praxis, puede ser útil para iluminar la situación concreta de América Latina. Pues bien, la importancia de la filosofia de la praxis para los movimientos de liberación latinoamericanos se puede examinar en tres direcciones principales: en una dirección cientffica, en una dirección crítica y en una dirección práctico-utópica.

Desde una perspectiva cientifica, es indudable el aporte que al análisis manxista puede ofrecer $-y$ de hecho ha ofrecido y está ofreciendo- para explicar la dinámica estructural de nuestros capitalismos dependientes. Esta importancia del análisis socio-económico maxista para dar cuenta de los mecanismos de explotación que imperan en nuestras sociedades es reconocida por todos aquellos que se preocupan seriamente por las consecuencias del subdesarrollo y la dependencia. Este es el caso, por ejemplo, de muchos teólogos de la liberación ${ }^{97}$. que han encontrado en los planteamientos de Marx un instrumental analítico de gran valor para develar los mecanismos y la 'lógica y la civilización del capital' que ha sumido a las mayorlas populares de nuestros paises en la más absoluta miseria y degradación material y espiritual.

Desde su componente crítico-humanista, la filosofia de la praxis es de gran importancia y actualidad en el contexto latinoamericano. Por un lado, desde ella es posible ponderar los reales alcances deshumanizadores de los capitalismos dependientes, es decir, la profundidad y consecuencias a nivel social $e$ individual que produce una explotación rapaz y sin limites. Por otra parte, la criticidad propia del pensamiento de Marx, al ser asumida por los diferentes movimientos revolucionarios de inspiración marxista que luchan por la liberación de las mayorias populares del subcontinente, puede contribuir a su crecimiento ético y 
politico; mejor aún, puede convertirse en un elemento antidogmático importante y necesario para realizar una praxis liberadora 'a la altura de los tiempos'. Si la felicidad humana se convierte en el eje y fin de la lucha revolucionaria, no tiene porque haber planteamientos teóricos 0 politicos que sean contrarios o que estén por encima de los sujetos y agentes del proceso de liberación. Es decir, el humanismo de Marx ensena a relativizar todas las posiciones a partir y desde ese único absoluto que -desde el atelsmo maxista - es el hombre y su felicidad.

Desde su proyecto de transformación del orden establecido, Marx ofrece orientaciones práctico-políticas cuya finalidad es incidir en la lógica estructural del orden burgués. No hay que olvidar que el capitalismo es el modo de producción dominante en América Latina. Sin embargo, la propuesta marxista para su transformación estructural no debe tomarse como una "receta" válida para todo tiempo y lugar. En cada caso concreto, esa propuesta debe contrastarse y enriqueserse y también corregirse- con la dinámica histórica particular que se quiere transformar. La contribución que Marx hace, en este punto, a los movimientos de liberación latinoamericanos, más que en la línea de las "recetas", va en la línea de la radicalidad y la apertura hacia el futuro del obrar revolucionario. Es decir, lo que Marx ensena a los revolucionarios es a no conformarse nunca con lo alcanzado, ya que ningún orden social concreto expresa definitivamente to que es la realización plena del hombre.

El comunismo, como 'horizonte utópico', está más allá que cualquier realización socio-histórica concreta: es la meta futura - nunca alcanzable- que recuerda a la humanidad el largo camino que la falta todavla que recorrer para ser verdaderamente humana. Los "socialismos reales" olvidaron esta herencia de Marx, y cuando hombres lúcidos como Ernest Bloch lo recordaron la respuesta del Partido fue la persecución y en muchos casos el asesinato político. Los revolucionarios latinoamericanos tienen ante si el gran reto de hacer que la historia no se repita. Esta es otra de las grandes lecciones que el tercer mundo puede dar al primer mundo: cómo hacer una revolución socialista que tenga como principio y fin la humanización de los hombres y que esté abierta al futuro, es decir, que esté abierta a nuevas revoluciones y transformaciones en su propia realidad.

\section{Notas}

1) Rubel, M., Karl Marx: ensayo de biografia intelectual. Buenos Aires. Paidós, 1970. p. 172 
2) Sánchez Vázquez, A., "Mi obra filosófica". En Praxis y filosofla. Ensayos en homenaje a Adolfo Sánchez Vázquez. México, Grijalbo, 1985. p. 442

3) Marx, K., "Tesis sobre Feurbach", (I y III), en la Ideologla alemana. La Habana, Pueblo y educación, 1984. pp. 633-34

4) Kosik, K., Dialéctica de lo concreto. México, Grijalbo, 1969. p. 240.

5) Cerroni, U., La teoría de las crisis sociales en Marx. Madrid, Alberto Corazón Editor, 1975. p. 34

6) Ibid.

7) Marx, K., Ideologla alemana. Edición citada, p. 77

8) Ibid. p. 77

9) Marx, K., El Capital, I, México, FCE, 1972. p. 270

10) Ibid. pp. 269-270

11) Ibid. p. 266

12) Mandel, E., Tratado de economía marxista. México, ERA, 1972. pp. 266 y 158-159

13) Ibid. pp. 159-160

14) Ibid.

15) Marx, K., Elementos fundamentales para la critica de la economla politica (Grundrisse), I, México, Siglo XXI, 1986. p. 77

16) Marx, K., El Capital, III, edición citada, p. 243

17) Ibid. p. 244

18) Bianchi, M., La teoria del valor desde los clásicos a Marx. Madrid, Alberto Corazón Editor, 1975. p. 123

19) Ibid. p. 46

20) Ibid.

21) Ibid. p. 47

22) Ibid. p. 48

23) Smith, A., La riqueza de las naciones. Citado por Fiorito, R., en División del trabajo y teoría del valor. Madrid, Alberto Corazón Editor, 1974. p. 89

24) Fiorito, R., ob. cit., p. 89

25) Bianchi, M., ob. cit., p. 48

26) Ibid. p. 49

27) De Giovanni, B., La teoría política de las clases en 'El Capital'. México, Siglo XXI, 1984. p. 24

28) Ibid.

29) Ibid. p. 25

30) Bianchi, M., ob. cit., p. 50

31) Smith, A., La riqueza..., en ob. cit., nota 23, p. 50

32) Ibid.

33) Bianchi, M., ob. cit., p. 60

34) Ibid.

35) Marx, K., ob. cit., nota 9, pp. 124-144

36) Bianchi, M., ob. cit., pp. 70-71

37) Ibid. pp. 72.74

38) Sik, O., La tercera vía. México, FCE, 1977. p. 110

39) Garaudy, R., ¿Se puede ser comunista hoy? México, Grijalbo, 1970. p. 42 
40) Ollman, B., Alienación. Marx y su concepción del hombre en la sociedad capitalista. Buenos Aires, Amorrortu, 1973. p. 243

41) Rubel, M., ob. cit., p. 277

42) Marx, K., ob. cit., nota 9, p. 55

43) Ibid. p. 608

44) Rubel, M., ob. cit., pp. 283-284

45) Ollman, B., ob. cit., p. 238

46) Marx, K., ob. cit., nota 15, p. 4

47) Marx, K., ob. cit., nota 9,p. 130

48) lbid. pp. 131-133

49) Ibid. p. 137

50) Rubel, M., ob. cit., p. 383

51) Marx, K.,"Salario, precio y ganancia". En Marx, K. y Engels, F., Obras escogidas. Moscú, Progreso, s.f., p. 225

52) Marx, K., ob. cit., nota 9, p. 267

53) Marx, K., Miseria de la filosofla. México, Siglo XXI, 1978. pp. 125-127

54) Marx, K., ob. cit., nota 9, pp. 274-285

55) Ibid. cap. XIII, sección 3

56) Mandel, E., ob. cit., pp. 161-162

57) Marx, K., ob. cit., nota 9, p. 270

58) Ibid. p. 266

59) Mandel, E., ob. cit., p. 158

60) Marx, K., ob. cit., nota 15, pp. 77 y 275

61) Marx, K., ob. cit., nota 16, p. 244

62) Marx, K., "Trabajo asalariado y capital". En ed. cit., nota 51, p. 88

63) Marx, K., ob. cit., nota 15, p. 236

64) Dussel. E., La producción teórica de Max. Un comentario de los Grundrisse. México, Siglo XXI, 1985.p. 340

65) Marx, K., ob. cit., nota 16, p. 248

66) Ibid.

67) Grossman, H., La ley de la acumulación y el derrumbe del sistema capitalista. México, Siglo XXI, 1979. p. 9

68) Ibid. p. 65

69) Rubel, M., ob. cit., p. 288

70) Cerroni, U., ob. cit., p. 226

71) Grossman, H., ob. cit., p. 388

72) Marx, K., "Carta de Marx a Engels del 28 de abril de 1868" citada por Grossman en ob. cit., p. 388

73) Marx, K., ob. cit., nota 51, p. 232

74) Grossman, H., ob. cit., p. 389

75) Marx, K., ob. cit., nota 15, p. 85

76) Cerroni, U., ob. cit., p. 356

77) Rubel, M., ob. cit., p. 286

78) Marx, K., ob. cit., nota 9, p. 43

79) Ibid.

80) Ibid. p. 44 
81) Ibid.

82) Marx, K., ob. cit., nota 15, p. 100

83) Dussel, E., ob. cit., p. 90

84) Mandel, E., ob. cit., p. 166

85) Ibid. p. 166

86) Marx, K., ob. cit., nota 15, p. 89

87) Mandel, E., ob. cit., p. 166

88) Bianchi, M., ob. cit., p. 140

89) Marx, K., citado por Rubel, M., en ob. cit., p. 288

90) Bianchi, M., ob. cit., pp. 147-165

91) Ibid. pp. 165-166

92) Colleti, L., "¿Marxismo scienza o rivoluzione?", citado por Bianchi, M., en ob. cit., p. 166

93) Ibid.

94) Ibid. p. 167

95) Cerroni, U., ob. cit., p. 257

96) Cfr. Mardones, J.M., Capitalismo y religión. La religión polfitica neoconservadora. Inédito.

97) Cfr. Ellacurla, I., "Teología de la liberación y marxismo". RLT, 20, 1990. pp. 109-136; Boff, L. y Boff, C., Cómo hacer teologla de la liberación. Bogotá, Ediciones Paulinas, 1986. 